\title{
The Impact of Social Business Process Management on Policy-making in e-Government
}

\author{
Yiwei Gong \\ School of Information Management \\ Wuhan University \\ yiweigong@whu.edu.cn
}

\author{
Marijn Janssen \\ Faculty of Technology, Policy and Management \\ Delft University of Technology \\ M.F.W.H.A.Janssen@tudelft.nl
}

\begin{abstract}
The combination of social media and Business Process Management (BPM) has given rise to the emerging field of "social BPM". The new development of social BPM is expected to provide benefits like flexibility for knowledge-intensive processes, like policy-making. The goal of this paper is to understand the impact of social BPM on policy-making. We first present a literature survey showing that social $B P M$ is a new and emerging research area and limited attention has been given to social BPM in egovernment. The literature reviews showed a lack of empirical research into the accomplished benefits of social BPM. To bridge this gap, a comprehensive case study in a Dutch government social BPM platform was conducted. While not all the benefits suggested in the literature were identified in the case study, negative impact of social BPM were also found. A tension was found between accomplishing flexibility and accountability and user efficiency.
\end{abstract}

\section{Introduction}

Government's policies need to address societal needs, changing preferences of citizens, advances in technology and social or regulation issues to serve their citizens better. To deal with these changes policymaking processes need to be sufficiently flexible to adapt within a relatively short time frame. Flexibility can be defined as "ability of organizations to respond to changes in the environment" [1](p.64). Hard-coded business processes and legacy systems often prevent organizations from being able to adapt within a short time frame. BPM tools are aimed at automating and controlling business processes. Traditional BPM tools often provide limited flexibility. These tools focus on the automation of repeatable and standardized business processes, which do not change often [2].

Business processes for policy-making in governmental organizations are often knowledge-intensive. Policy-making is often an unstructured and highly complex process in which many stakeholders are involved [3]. Policy-making processes usually contain tasks to be performed by highly-skilled staff having particular knowledge and expertise. Often the expertise within the own organizations is limited and experts outside the own organizations are involved depending on the problem at stake. A variety of experts is often involved in policy-making in which everybody brings some expertise to the table [3]. Policy-making in governmental organizations typically deals with complex issues such as local development strategy, pollution remediation, sustainable energy, and international trade and so on. These processes often involve various stakeholders and they are hard to structure and to automate in advance [4].

In todays' internet-supported working environment, policy-makers employ more and more their social networks for daily communication, cooperation and knowledge sharing. Social network offers the opportunity to improve the communication among all the stakeholders [5]. The use of social media is often ad-hoc and not embedded in the business processes, whereas utilization of knowledge is a key aspect.

The extension of BPM with social media is viewed as a new paradigm in BPM research $[6,7]$. Social BPM refers to BPM practices with integrated social media applications. Social BPM aims at enhancing the organization's performance by means of a controlled participation of stakeholders to process design and enactment [8](p.223). The concept of social BPM enables a large variety of experts from within and outside the organizations to contribute their domain knowledge and expertise to certain tasks within a business process [9]. This feature of social BPM is expected to create flexibility for organizations to tackle different type of problems $[2,8,10$, 11]. Yet there is limited evidence of the accomplishment of the various benefits of social BPM in practice and there is void of research into the use of social BPM for policy-making.

A limited number of studies was found in literature regarding the underpinnings of social BPM and how social BPM is able to overcome some of the limitations of traditional BPM systems. Some preliminary studies have produced models at a conceptual level suggesting possible mechanisms to implement social BPM [c.f. 8, 10, 11]. But there is limited empirical research investigating the effect of social BPM in organizations. In this paper, the impact of social 
BPM for policy-making by governments is evaluated. For this purpose, literature is surveyed and a case study of a social BPM platform in the Dutch government is investigated. The significance of this research is twofold. On the one hand, it provides insight into whether the social BPM paradigm results in benefits like process flexibility. On the other hand, it provides insight into the use of social BPM and in particular how the benefits are achieved.

This article proceeds by providing a background on social BPM and its benefits for organizations in Section 2. Based on these two pillars, a social BPM case study for policy-making in governments is described and analyzed in Section 3. Section 4 discusses the case study findings. Finally, conclusions are drawn and future research directions are presented in Section 5 .

\section{Background}

To understand the state-of-the-art of social BPM research, we conducted a literature survey by searching a number of literature databases including the Web of Science, Sciencedirect, Wiley Online Library, Taylor \& Francis Online, SpringerLink, JSTOR, ACM Digital Library and IEEE Xplore. The literature survey was conducted in April 2016 by searching ("social" AND ("business process" OR "business process management" OR "BPM")) in article titles. This resulted in the identification of 35 conference articles and 7 journal articles focusing on social BPM published in the period from 2006 to 2016. The limited number of conference and journal articles on social BPM confirms the emerging nature of this topic. In this section, the concept of social BPM and its benefits will be discussed based on the literature survey.

\subsection{What is social BPM?}

The definitions of social BPM in the literature were found to be ambiguous. In most of the work there is an agreement that social BPM is a combination of social software technology and BPM, and the literature emphasizes the role of social media enabled collaboration, e.g. [8, 12, 13]. More formal definitions of social BPM include the concept of process lifecycle (i.e. process design, configuration, enactment and diagnosis [14]) and stresses the role of social media effecting all the stages of the lifecycle, and how the effect is achieved. For example, Pflanzl and Vossen define social BPM as "the involvement of all relevant stakeholders in a BPM life cycle by applying social software and its underlying principles" [9] (p.3870).

Various applications of social BPM have been suggested in the literature. Most of these approaches aim to support the identification and allocation of expertise in a social network environment for a better business process design. For example, Liu et al. [15] presented a novel resource model that incorporates the concepts of resource communities and social positions to facilitate the identification of required knowledge and skills. Schall, et al. [16] proposed a ranking method based on Hyperlink-Induced Topic Search algorithm to estimate the expertise of knowledge workers in a social network. With a similar motivation for identifying expertise but using a different approach, Karni and Levy [17] employed a tagging model in BPM for identifying expertise. A similar approach of using tagging was found in [10], where the post execution tagging of business process $\operatorname{logs}$ is utilized to assist future process participants by providing recommendations for task design and role assignment. In addition, there are also studies on tools for facilitating participation of stakeholders in the stage of process design. For example, Brambilla and Fraternali [8] extended the classical BPMN techniques with the aid of specific notations that enable the addition of social processes such as web applications along public or private Web social networks. Santorum, et al. [11] designed and developed a participative method called ISEA for process design and modeling. In [18] a SOA-based approach was presented for reengineering Enterprise Social Networking into Web services, in order to facilitate collaboration and participation in business processes. Although the latter definition of social BPM advocates the use of social software technologies at all stages of the BPM lifecycle, the above pilot approaches have in common the focus on technical solutions for the design and configuration stage of business processes. Social BPM's effect on the enactment and diagnosis stage has not be given enough attention. This requires empirical studies to investigate how social BPM is applied in practice.

However, the literature survey showed that there were only a few empirical research studies providing an in-depth understanding of how social BPM could be applied on knowledge-intensive business processes. Table 1 provides an overview on the empirical case studies found in the literature survey. Those case studies all employed a single case study design.

Table 1. Overview of empirical research on social BPM in literature

\begin{tabular}{|l|l|}
\hline $\begin{array}{l}\text { Empirical case } \\
\text { study context }\end{array}$ & Problems to be addressed \\
\hline $\begin{array}{l}\text { Small to Medium } \\
\text { Sized Enterprise }\end{array}$ & $\begin{array}{l}\text { How to identify actual working } \\
\text { relationships among employees } \\
{[19]}\end{array}$ \\
\hline Healthcare & $\begin{array}{l}\text { How the use of Social BPM } \\
\text { eases the cooperative design of } \\
\text { social processes, and their coop- } \\
\text { erative execution [20] }\end{array}$ \\
\hline University & $\begin{array}{l}\text { How to automatically discover } \\
\text { and combine the appropriate } \\
\text { gadgets into workflows [21] }\end{array}$ \\
\hline
\end{tabular}




\begin{tabular}{|l|l|}
\hline $\begin{array}{l}\text { IT service deliv- } \\
\text { ery organization } \\
\text { of a large compa- } \\
\text { ny }\end{array}$ & $\begin{array}{l}\text { How to have governance to an } \\
\text { existing enterprise wiki designed } \\
\text { for capturing, collaborating on, } \\
\text { and evolving best practice busi- } \\
\text { ness process assets [22] }\end{array}$ \\
\hline
\end{tabular}

All case studies in Table 1 address different type of problems in knowledge-intensive processes within different context. The number of case studies is limited. While most of those case studies dealt with the design and configuration stage of processes, the scope of [20] also concerns the process enactment. All cases have in common that they address a technical 'how to' question in the application of social BPM, but no or limited attention is given to the evaluation of its impact to users and organizations. At the same time the e-government area is hardly addressed. Only 2 conference papers $[8,18]$ were found mentioning social BPM in the government context, while another paper [23] mentions the application of social BPM in governments as potential application domain. None of the studies focuses on policy-making processes.

\subsection{Benefits of social BPM}

Business processes are often designed and managed by business experts and IT professionals according to given requirements. This traditional way of BPM goes well with simple, standardized and routine work. However, knowledge-intensive organizations face complex problems, which are dynamic. There is no standard approach to tackle them. Policy-making processes can be large different each time and they are difficult to define in advance. For dynamic and ad-hoc business processes, social media offers a more flexible and effective way of management during the business process life cycle [24]. In the literature, the use of social media in BPM can bring a number of benefits to organizations as listed in Table 2 .

Table 2. Benefits of social BPM in literature

\begin{tabular}{|c|c|c|}
\hline Level & Social BPM benefits & Sources \\
\hline \multirow{3}{*}{ Strategic } & $\begin{array}{l}\text { B1: Improving the ex- } \\
\text { change of knowledge and } \\
\text { information }\end{array}$ & $\begin{array}{lr}{[5,6,8,} \\
17, & 25- \\
27] & \\
\end{array}$ \\
\hline & B2: Speed up decisions & $\begin{array}{ll}{[8,} & 25, \\
28] & \\
\end{array}$ \\
\hline & $\begin{array}{l}\text { B3: Access to external } \\
\text { intelligence resources }\end{array}$ & {$[16,29]$} \\
\hline \multirow{3}{*}{ Operational } & $\begin{array}{l}\text { B4: More flexibility or } \\
\text { adaptability }\end{array}$ & $\begin{array}{l}{[6, \quad 10,} \\
13, \quad 26, \\
27,30]\end{array}$ \\
\hline & $\begin{array}{l}\text { B5: Foster mutual under- } \\
\text { standing, transparency of } \\
\text { process issues and joint } \\
\text { problem solving }\end{array}$ & $\begin{array}{l}{[5,6,8,} \\
26, \\
29]\end{array}$ \\
\hline & $\begin{array}{l}\text { B6: Better coping with } \\
\text { incidents }\end{array}$ & {$[25]$} \\
\hline
\end{tabular}

\begin{tabular}{|l|l|l|}
\hline & $\begin{array}{l}\text { B7: Enhancing sugges- } \\
\text { tions for process im- } \\
\text { provement }\end{array}$ & $\begin{array}{l}{[5,25,} \\
31,32]\end{array}$ \\
\hline Individual & $\begin{array}{l}\text { B8: Reduce learning } \\
\text { curves for business users } \\
\text { and increase productivity }\end{array}$ & {$[32]$} \\
\hline
\end{tabular}

A list of benefits of social BPM ranging from the strategic to the individual was found in the literature survey. We also found that most benefits are deduced from the conceptualization of social BPM or from other literature. There is no empirical evidence to prove the benefits of social BPM in practice. As we found from the literature survey, many proposed approaches or tools are still in their pilot stage and have not yet been used in practice, while empirical case studies are very limited as there exist no appropriate social BPM tools for practitioners.

One important benefit that is highlighted in literature is that flexibility is created by social BPM. Social BPM enables users to find, learn about and connect with the right people, information and other resources to deal with unanticipated situations, thus promoting process flexibility [13]. Specifically, social BPM promotes flexibility from three dimensions [26]: 1) community organization: enabling bottom-up development of a shared knowledge space within an organization or in the public by collaboration and access; 2) object specificity: allowing for development of a process document with a semi-formal structure; 3) degree of completeness: facilitating continuous evolution rather than development of a final version of process design (infinite vs. finite number of review cycles). The use of social BPM to gain greater flexibility in e-government was demonstrated by use cases $[8,18]$. This reflect the needs in applying social BPM in government organizations and further research in the enactment and diagnosis stage of social BPM in government context.

\subsection{Summary}

The literature review revealed a number of shortcomings in the state-of-the-art of the literature. First, the studies of social BPM are conducted in a number of 'trial-and-error' attempts [29], which are designoriented with a focus on proposing technical approaches for social BPM. Given the fact that social BPM is a new research area, it is not surprising that most approaches found in the literature survey are focusing on the early stage of BPM lifecycle: the process design and configuration [28] and not on the execution. This is understandable, as those approaches and tools should first be able to support the earlier stages and can only thereafter be executed. None of the case studies found in the literature survey investigated the effect of social media on the enactment and diagnosis stage. Case study research can help to understand better the role of social media in the full 
process lifecycle, while different industries might have their specific problems to be addressed.

Second, literature mentions many the benefits of social BPM. Much of the literature has an explorative nature and contains assumed benefits, instead of empirically proven benefits. Possible negative impact of social BPM has been given less attention. Hence, comprehensive case studies are desired to reveal the benefits of social BPM and the cost which we have to pay for achieve those benefits.

Finally, most of the literature focused on companies and limited attention has been given to governments. To understand the impact of social BPM on governments, a case study of social BPM practice in Dutch government agencies was conducted.

\section{Social BPM practice in governments}

A descriptive case study was conducted using the literature review as a frame of reference. The list of benefits originating from the literature were used as a starting point and further refined in the case. The user interactions were analyzed by following interactions and mapping them to create an overview of the processes. This helped us to gain a deep understanding of the working of social BPM in practice and to see how the benefits of social BPM are created.

Pleio (www.pleio.nl) is a social network for Dutch civil servants which was initiated to utilize the fragmented knowledge of governments better. Pleio was initiated in 2011 to bring together the capabilities of public servants which are fragmented around many levels and organizations. Collaboration beyond the boundaries of their own organizations should provide access to knowledge else outside of reach. Nowadays, Pleio has more than 350,000 users.

On Pleio, users can create or join online communities to collaborate, share files including documents, pictures and video, update statuses and profiles, write blogs and wikis, manage agendas, create sub-sites, connect with others and send messages etc. This can be done within or across the boundaries of government agencies, as well as with non-governmental partners and citizens. Pleio provides the flexibility for public organizations to create an online presence of existing offline functions, and also to create and add a new one. In addition, Pleio is an open network and supports linking to social networks liked Facebook, LinkedIn and Twitter.

\subsection{Use of social BPM}

Pleio can be used by governments to search for experts which can contribute and participate in their policy-making processes. In this way a whole-ofgovernment approach is created in which experts and policy-makers from many governmental organizations are able to find each other and subsequently collaborate together. A great variety of processes and partnerships are supported by Pleio, from the coordination for some very large government program, like the Delta project, to the daily communication between administrators of a small municipality, like Haarlem. Within the many communities on Pleio, the one created and coordinated by the former Government Service for Land and Water Management (Dienst Landelijk Gebied, DLG) is a typical example of a social BPM application that will be explained in more detail.

The implementation of DLG's projects is typically carried out in partnership with provinces and municipalities, land manager agencies such as the Forestry Commission, and other organizations such as Public Works. Not only government agencies are involved in redevelopment of areas. DLG's projects are often the interests of multiple actors such as Nature Reserves and provincial landscape administrators, as well as environmental organizations. In addition, residents and businesses in the area are often involved and participate in the policy-making process.

Through online and offline participation, opinions and knowledge of local residents are gathered. Various opinions of stakeholders are brought together for the developments of policies concerning the redevelopment of the area. The involvement of various stakeholders into a policy-making process goes along with a diffusion of the redevelopment project information in the Pleio social network. Figure 1 provides an illustrative example to demonstrate how a DLG project is developed and how a policy-making process is dynamically created. The many connected spots represents the Pleio users and different colors are used to distinguish whether they are involved in the process. In an initiation stage, the project is often started by DLG and the municipality based on the need for local redevelopment (see Figure 1 (a)). During the policy-making, stakeholders are identified and invited to participate in the process based on their responsibility, interest and/or knowledge to specific issues (see Figure 1 (b)). Along with more stakeholders are involved, various opinions and interests are collected and presented to involved participants and potential participants. Different opinions are taken into account in parallel and new participants with required knowledge are invited into the process in order to balance different interests and to evaluate the policy. Finally, opinions, insights and facts are aggregated to arrive at a conclusions (see Figure 1 (c)). Figure 1 represents an over simplified situation. The actual situation was much more complicated, as participants entered and left the process and there is a wide variety of participants. 


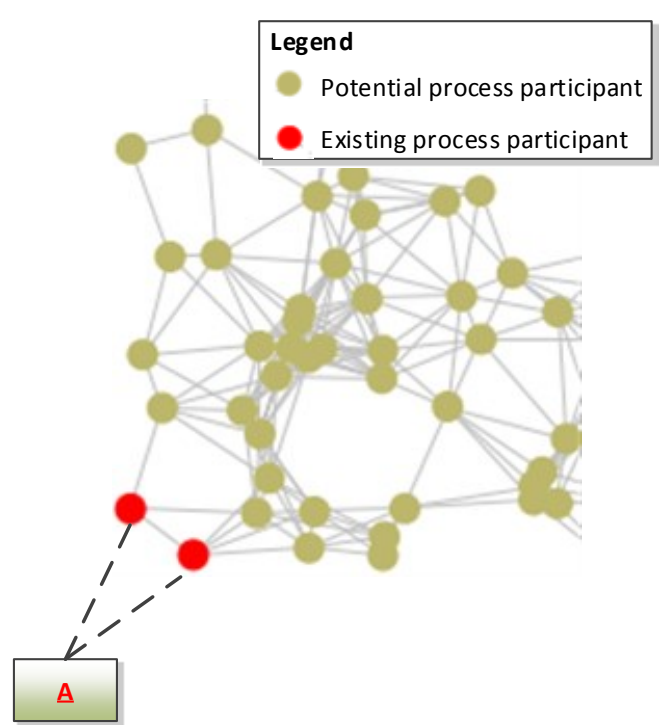

(a) Initiation of a policy-making process

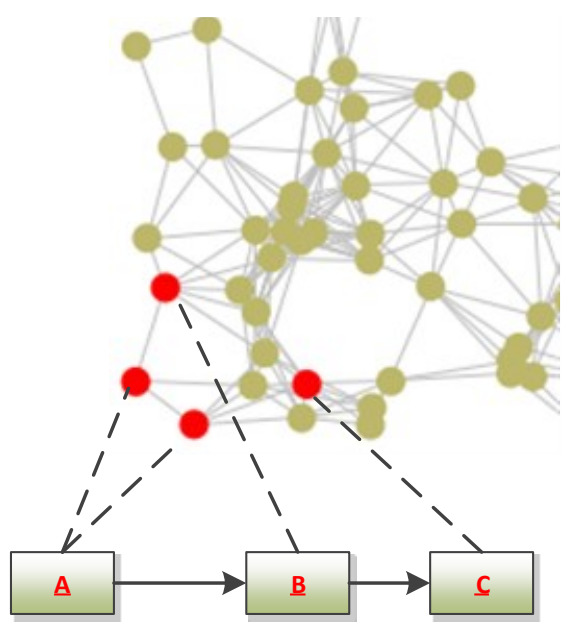

(b) Ongoing Process in which more stakeholders were involved to make progress

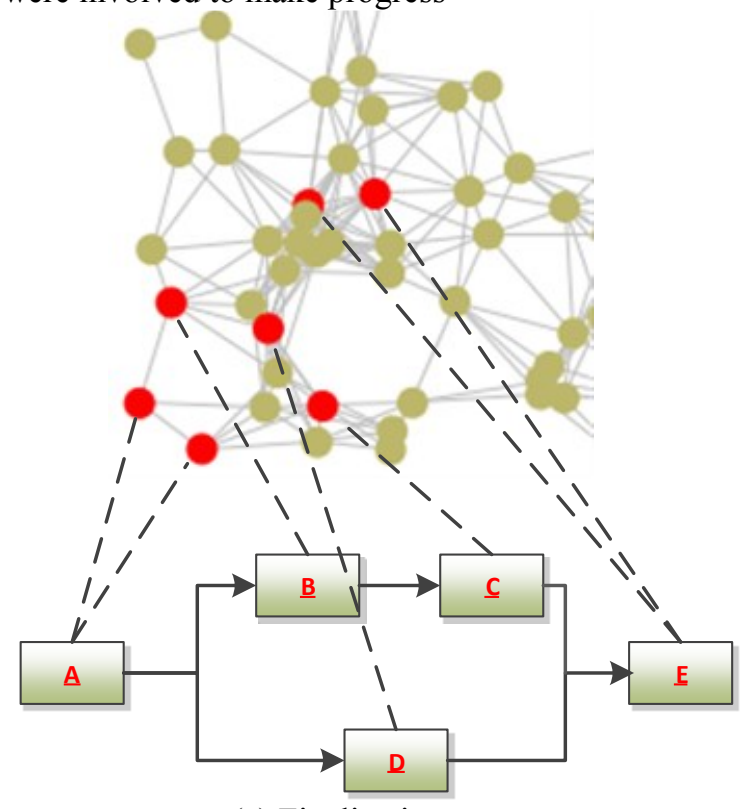

(c) Finalization stage

Figure 1. Visualization of a policy-making process in a DLG project
In the policy making process, DLG works as a coordinator connecting the various participants. Many parties are involved having their own interests and expertise, and DLG is the link between these parties to ensure that all interests are taken into account in the process. DLG ensures that the right parties sit at the table and facilitates collaboration and knowledge sharing across the borders of all these organizations supported by Pleio. Flexibility in policy-making is created by a dynamic adaptation of the process. When the process needs to be adapted to address different opinions and suggestions, the involvement of new stakeholders is recommended by the current parties at the table to fulfill the needed knowledge and balance conflicting interests. Process improvement and adaptation is typically followed by involving more expertise and extensive negotiations. However, this often requires multiple rounds of interaction and usually takes a long time. When more opinions are taken into account, the decision-making becomes more complex and needs more time. Nevertheless the quality of decision-making can be higher and more commitment can be created.

The application of social BPM also changes the structuredness of DLG's redevelopment projects. By using Pleio, the policy-making process shifts from being a hierarchical implementation to a co-creation network. This also requires a shift in the role and the way of working of policy-makers. The process is no longer driven by the organizational structure. Instead, it is driven by the need of the stakeholders. Each project consists of a network of connections and a web of partnerships. For each new project, policymaker starts creating a new network with colleagues from their own organization, officials of other governments and people from outside of the own organization. This allows to have access to the desired expertise and to ensure that that right organizations are involved.

Also the people involved have to adapt their work processes to take advantage of social BPM. For those managing the process, there is a need for new capabilities and skills. In particular, they need to keep monitoring the ongoing process and paying attention to the discussions of various topics in the online community. This requires extensive online communication skills and also the capability to process fragmented information often in fragmented pieces of time among other daily work.

\subsection{Benefits of social BPM in practice}

Our case study of social BPM shows that a number of benefits are accomplished. These benefits conformed several of the benefits as found in the literature. Table 3 explains the relationship between the benefits found in the literature survey and those found in our case study. 
Table 3. Benefits of social BPM in the case study

\begin{tabular}{|c|c|}
\hline Benefits & Findings in the Pleio case study \\
\hline B1 & $\begin{array}{l}\text { Pleio gives every public servant the op- } \\
\text { portunity to be the subject of bringing } \\
\text { people together and sharing knowledge, } \\
\text { whether it is a knowledge network for } \\
\text { colleagues, an alliance of organizations } \\
\text { or a project team that works together. In } \\
\text { addition, governments and other public } \\
\text { bodies may use Pleio to create their own } \\
\text { interactive sites or platforms. Such a } \\
\text { subsite can have its own design and its } \\
\text { own Internet address and can be just like } \\
\text { a real town hall or government building } \\
\text { that is used for various purposes and } \\
\text { made available to different audiences, } \\
\text { both for internal use and for co-creation } \\
\text { with the community. }\end{array}$ \\
\hline $\mathrm{B} 2$ & No support for this benefit. \\
\hline B3 & $\begin{array}{l}\text { Pleio enables collaboration across the } \\
\text { organizational boundaries. It is cloud- } \\
\text { based and not restricted to the IT envi- } \\
\text { ronment of the organization. Pleio ena- } \\
\text { bles access to resources and expertise that } \\
\text { is not available within a user's own or- } \\
\text { ganization. }\end{array}$ \\
\hline B4 & $\begin{array}{l}\text { Flexibility is created by connecting dif- } \\
\text { ferent stakeholders in the process of poli- } \\
\text { cy-making and extensive negotiation to } \\
\text { enable adaptations. }\end{array}$ \\
\hline B5 & $\begin{array}{l}\text { In Pleio, users can open a group to bring } \\
\text { people together around a theme, file, } \\
\text { project or case. Such an "online meeting } \\
\text { room" may be open or closed. Different } \\
\text { functionalities are available to share or } \\
\text { collaborate knowledge, such as discus- } \\
\text { sion forums and writing a document to- } \\
\text { gether. In this way, Pleio can be used as a } \\
\text { teamwork environment and a platform for } \\
\text { co-creation. }\end{array}$ \\
\hline B6 & No support for this benefit. \\
\hline B7 & $\begin{array}{l}\text { Fulfilling knowledge gaps allows for } \\
\text { process improvement. }\end{array}$ \\
\hline B8 & No support for this benefit. \\
\hline
\end{tabular}

Five out of the eight benefits mentioned in the literature were found in our case study. The unconfirmed benefits are about the speed of decisionmaking (B2), the capability of dealing with incidents (B6) and personal learning and productivity (B8). We will discuss these in the findings and discussion section.

\subsection{Disadvantages of social BPM}

Despite the many benefits, also drawbacks were found. Some of the drawbacks are attributed to a lack of functionality of Pleio. For example, the lack of intelligent data processing support resulted in an information overload. Other disadvantages seem to be intrinsic to social BPM, like poorer accountability. Accountability is a relationship between two parties, in which an individual or agency is held to answer for a performance that involves some delegation of authority to act [33]. An example of poorer accountability is that the involvement of stakeholders is not determined in advance but recommended by other stakeholders. Findings on negative impact of social BPM in the case study are listed in Table 4.

Table 4. Negative impact of social BPM in the case study

\begin{tabular}{|c|c|c|}
\hline Level & $\begin{array}{c}\text { Negative } \\
\text { impact }\end{array}$ & Explanation \\
\hline \multirow{3}{*}{$\begin{array}{l}\text { Strate- } \\
\text { gic }\end{array}$} & $\begin{array}{l}\text { Poor pro- } \\
\text { ject plan- } \\
\text { ning }\end{array}$ & $\begin{array}{l}\text { Dynamic boundary of project } \\
\text { involvement makes it diffi- } \\
\text { cult to plan the project for } \\
\text { policy-making. }\end{array}$ \\
\hline & $\begin{array}{l}\text { Extra in- } \\
\text { vestment } \\
\text { to protect } \\
\text { privacy }\end{array}$ & $\begin{array}{l}\text { More effort is required to } \\
\text { secure organizational and } \\
\text { customer data on open plat- } \\
\text { forms }\end{array}$ \\
\hline & $\begin{array}{l}\text { Difficulty } \\
\text { in main- } \\
\text { taining } \\
\text { accounta- } \\
\text { bility }\end{array}$ & $\begin{array}{l}\text { Policy-makers should ac- } \\
\text { count for their actions, how- } \\
\text { ever, with limited repeatabil- } \\
\text { ity and traceability at the } \\
\text { operational level, accounta- } \\
\text { bility becomes a challenge. }\end{array}$ \\
\hline \multirow{6}{*}{$\begin{array}{l}\text { opera- } \\
\text { tional }\end{array}$} & $\begin{array}{l}\text { Less } \\
\text { efficiency } \\
\text { in commu- } \\
\text { nication }\end{array}$ & $\begin{array}{l}\text { Users might encounter with } \\
\text { many unnecessary updates, } \\
\text { incorrect information, and } \\
\text { consequentially, wasted time } \\
\text { and resources }\end{array}$ \\
\hline & $\begin{array}{l}\text { Infor- } \\
\text { mation } \\
\text { overload }\end{array}$ & $\begin{array}{l}\text { On an open platform, over- } \\
\text { heads of the contributions } \\
\text { greatly increase. Those con- } \\
\text { tributions are often unstruc- } \\
\text { tured data and require manu- } \\
\text { al processing. }\end{array}$ \\
\hline & $\begin{array}{l}\text { Low quali- } \\
\text { ty of in- } \\
\text { formation }\end{array}$ & $\begin{array}{l}\text { Excessive information does } \\
\text { not necessarily result in the } \\
\text { correct information. }\end{array}$ \\
\hline & $\begin{array}{l}\text { Low re- } \\
\text { peatability }\end{array}$ & Processes cannot be repeated \\
\hline & $\begin{array}{l}\text { Difficulty } \\
\text { in tracing } \\
\text { back }\end{array}$ & $\begin{array}{l}\text { How decisions are made } \\
\text { cannot be traced due to the } \\
\text { many interactions }\end{array}$ \\
\hline & $\begin{array}{l}\text { Loss of } \\
\text { data }\end{array}$ & $\begin{array}{l}\text { Using social media and not } \\
\text { storing all customer interac- } \\
\text { tions }\end{array}$ \\
\hline $\begin{array}{l}\text { Per- } \\
\text { sonal }\end{array}$ & $\begin{array}{l}\text { Extra time } \\
\text { and effort } \\
\text { investment }\end{array}$ & $\begin{array}{l}\text { Using social BPM has a lead } \\
\text { time to achieve its benefits, } \\
\text { therefore the users have to } \\
\text { invest time and effort for } \\
\text { some time to achieve bene- } \\
\text { fits in the future [2]. }\end{array}$ \\
\hline
\end{tabular}




\section{Findings and discussion}

Applying social BPM in governments can achieve several of the benefits that have been mentioned in literature. At the same time, achieving those benefits might also results in disadvantages. In other words, achieving some benefits like flexibility results in sacrificing other aspects, such as accountability.

\subsection{Impact of social BPM}

The case study findings indicate that a number of benefits as mentioned in the literature are not accomplished and that the creation of flexibility results in some negative impact. Whereas current processes are well-structured and focus on efficiency, social BPM is less-structured. Providing more flexibility seems to come at the expense of efficiency. Some persons were almost seduced by social media which consumed most of their time, leaving little time for other work. In particular, the customer contact is becoming increasingly time-intensive as customers are expecting a speedy response. The structure provides the procedures and rules which should be followed to ensure that the right stakeholders are involved, and decisions are made by the right person. In our case study, social BPM presents less control on participation. As a result, some of the common practices and steps in policy-making (e.g. having a clear decision point) were not followed. As such, we argue that flexibility provided by social BPM is at the expense of other aspects. The balancing flexibility and its interrelated aspects is the key in the design of social BPM.

Although literature suggests that social BPM can speed up decisions (B2), our case study did not reveal this benefit. In contrast, we found that social BPM can delay decision-making process because of the intensive interactions between stakeholders. Many suggestions from stakeholders might need to be considered which is resource-intensive and requires a proper evaluation. Furthermore, social BPM might be used to gain commitment for decisions. However, persons whose ideas are neglected or when they have the feeling that their opinions are not considered seriously might start resisting. This resistance again slows down the decision-making and causes more negotiations.

Coping with incidents (B6) is about the aggregation and fusion of knowledge to solve the interruptions of business processes [25]. This is the second benefit that our case study did not found. Incidents might refer to the interruption of known and repeatable business processes, while policy-making processes on a social BPM platform are often ad-hoc and unrepeatable. Facilitating the aggregation and fusion of knowledge might be a benefit that originates from the communication functions of social software. In a policy-making process, communication is necessary to acquire the knowledge of participants and also to collect their different opinions that might cause an 'interruption' of the current process.

Those who are managing the policy-making process have to give continues attention to the information flow originating from many stakeholders. In literature, a benefit is mentioned as that social BPM users could learn from the communication with various experts and use the knowledge into process to increase their productivity (B8). However, our case study did not confirm it: we did not find evidence that increasing knowledge sharing by social BPM results in the increase of productivity at an individual level. On the contrary, extra time and effort investment were needed by Pleio users. In this sense, the benefits of knowledge exchange (B1) achieved at the strategic level, as well as the benefits of transparency of process issue (B5) and process improvement (B7) achieved at the operational level all come at the expense of extra time and effort at the individual level.

\subsection{Understanding the positive and negative impact of social BPM}

Social BPM is a complex phenomenon which can be implemented and used in various ways. The way that social BPM is used determines whether the intended benefits will be accomplished. In our case study, we observed that also negative impact occur along with the benefits.

A comprehensive understanding on the coincidence of the positive and negative impact should be subject to more detailed research in order to generalize the findings. A study of the coincident impact could reveal the interrelationship between different aspects of social BPM. Impact could be either a positive or negative depending on how social BPM is utilized in a certain situation. For some situations, like routine processes needing a low involvement, social BPM might not be suitable. Furthermore, balancing different aspects is a typical part of the design phase. Typically, design aspects that need to be considered when realizing social BPM systems are flexibility, accountability, information quality, transparency, traceability, and user efficiency. This list might not be exhaustive and a single case study could not be able to figure out all the complex interrelationships among different aspects. Nevertheless, through our case study, we are able to conclude two pairs of aspects that need for balancing in the implementation and application of social BPM: flexibility and accountability, as well as flexibility and user efficiency. These will be discussed next.

\subsection{Need for balancing flexibility and ac- countability}

A tension was found between flexibility on the one hand and accountability on the other hand. This 
tension can be balanced during the design process. Current social BPM practice provides the necessary flexibility, but does not provide accountability. An explanation for this is that accountability is of particular importance for the public domain [34, 35] and there is hardly any literature focusing on the government context.

Accountability includes accountability before a process is executed, during execution and after a process has been executed [36, 37]. After execution and during execution accountability is reactive and can be created by logging, however, before execution accountability relating to a series of negotiated agreements from stakeholders [36]. There might be an inherent tension between flexibility and accountability, as flexibility results in business processes that are hard to predict in advances, whereas accountability requires predictable business processes, in which similar cases are treated in the same way.

The way of policy-making is changed by developments in information and communication technology. Explosive growth in data, computational power, and social media creates new opportunities for innovating the processes and solutions of evidence-based policy-making and research [38]. These approaches require that the evidence is stored and can be traced back. Evidence-based policy-making poses higher requirements on the processes, however, social BPM does often not facilitate this, although it is technically possible by properly labeling and indexing the related data. This suggests that software vendors should adapt their software better to match the requirements form governments.

\subsection{Need for balancing flexibility and user efficiency}

Realizing social BPM requires a change in working processes and procedures, but also requires other capabilities and skills of employees. Process flows change and become more flexible and less predictable. The unpredictable flow needs to be managed and monitored, which is more challenging.

Employees need to be able to work autonomous for doing their job, but at the same time they need to be able to collaborate with others people inside their own organizations and with outsiders. This means that sometimes they have to work with persons they do not know or did not work with before. At the same time, they will have to keep monitoring the flow, paying attention to new opinions and stakeholders, figuring out whether the discussion about a certain topic is relevant to them, clarifying ambiguity to avoid misunderstanding, and sometimes also defending their own interests. Keeping an eye on the dynamic flow is time-consuming in comparison with a traditional way of policy-making following routine and standardized flows. As much time and effort is taken in monitoring the flow, the user efficiency might be low, especially in the early and medium stages of policy-making.

Improving user efficiency requires a transformation in employees' way of working. In our case we observed that some people were able to adapt social BPM, whereas others were reluctant and preferred to stick to their traditional way of working. One reason for this is the overwhelming amount of information and the uncertainty regarding the flow. People are illprepared to handle this.

This suggests that social BPM software vendors should develop functions to increase the efficiency of users in dealing with the overwhelming amount of information that is generated by the online community in social BPM. Those functions could include more intelligent data processing that provides visible information overview to the current status of the policy-making process, helps users in identifying interesting and relevant information, collects arguments against and in favor, increases the accessibility to information via different channels (e.g. by PC and mobile devices), and so on.

\section{Conclusions and future work}

There is limited empirical research in social BPM. Most social BPM literature is written by proponents emphasizing the benefits of social BPM for organizations and provides little attention to the potential negative impact. The literature assumes that the benefits can be accomplished, however, there is limited empirical evidence for this. This paper is one of the first work of investigating social BPM in the area of government. Our literature survey shows that this is the first work to report an in-depth case study to gain deep understanding of the impact of social BPM on policy-making processes and the underlying tradeoffs between different aspects.

Social BPM results in benefits like improving the exchange of knowledge and information (B1), accessing to external intelligence resources (B3), more flexibility (B4), fostering process transparency (B5) and enhancing process improvement (B7). Our research confirmed most of the benefits of social BPM mentioned in literature, although not all. The literature suggests that social BPM can speed up decisions (B2), increase the capability of dealing with incidents (B6) and enhance personal learning and productivity (B8), but our case study did not confirm these three benefits. On the contrary it shows that social BPM can reduce the speed, result higher complexity and might result in the need to invest extra time and efforts of individuals. The case study reveals also that social BPM might have some adverse effects. In particular, high level of flexibility might be at the expense of accountability and user efficiency.

There is hardly any work focusing on social BPM for governments. In our case study we found that the social BPM applications did not take the idiosyncrat- 
ic characteristics of governments into account. In governments, accountability is an important requirement, which suggests that software vendors should adapt their software better to match the requirements from governments. Social BPM can result in ad-hoc processes which might not meet the requirements originating from the legislative environment. The design of social BPM should make a careful trade-off to balance aspects like flexibility and accountability and user efficiency. This also suggests that private sector practices of social BPM might not be easily translated to the government which deals with aspects like accountability.

The single descriptive case study presented in this research has its limitation in understanding the interrelationships between a limited numbers of aspects. The case study is also dependent on the government context. In future research, it would be worthwhile to investigate how flexibility is generated and its interrelationships with other aspects in social BPM. This can help software vendors and designers to improve their social BPM software and applications. We recommend to have action-design research in social BPM to better elicit the unique requirements in relationship to the government context. More case studies about social BPM in governments are desired and simulation of how the variables influence each other can help designers to gain understanding of the complex interrelationship without having to experiment in practice.

\section{Acknowledgement}

This work is supported by the National Natural Science Foundation of China (Grand No. 71501145).

\section{References}

[1] Y. Gong and M. Janssen, "From policy implementation to business process management: Principles for creating flexibility and agility," Government Information Quarterly, vol. 29, pp. 61-71, 2012.

[2] M. Kocbek, G. Jošt, and G. Polančič, "Introduction to Social Business Process Management," in Knowledge Management in Organizations, L. Uden, M. Heričko, and I.-H. Ting, Eds., ed: Springer, 2015, pp. 425-437.

[3] J. J. Stewart, D. M. Hedge, and J. P. Lester, Public Policy: An Evolutionary Approach, 3 ed. Boston, USA: Cengage Learning, 2007.

[4] Y. Gong and M. Janssen, "From Software-Based To Knowledge-Based Policy Implementation and Compliance," International Journal of Public Administration in the Digital Age, vol. 1, pp. 108-127, 2014.

[5] A. Fleischmann, W. Schmidt, and C. Stary, "SubjectOriented BPM = Socially Executable BPM," presented at the the 15th IEEE International Conference on Business Informatics, Vienna, Austria, 2013.

[6] G. Bruno, F. Dengler, B. Jennings, R. Khalaf, S. Nurcan, M. Prilla, et al., "Key challenges for enabling agile BPM with social software," Journal of Software
Maintenance and Evolution: Research and Practice, vol. 23, pp. 297-326, 2011.

[7] P. Trkman and M. Klun, "Leveraging Social Media for Process Innovation. A Conceptual Framework," in BPM Driving Innovation in a Digital World, J. Vom Brocke and T. Schmiedel, Eds., ed: Springer, 2015, pp. 59-73.

[8] M. Brambilla and P. Fraternali, "Combining social web and BPM for improving enterprise performances: the BPM4People approach to social BPM," presented at the the 21 st International Conference on World Wide Web Lyon, France, 2012.

[9] N. Pflanzl and G. Vossen, "Challenges of Social Business Process Management," presented at the 47th Hawaii International Conference on System Science, Hawaii, USA, 2014.

[10] M. E. Rangiha and B. Karakostas, "The Use of Social Tagging in Social Business Process Management," presented at the Web Information Systems Engineering WISE 2014 Workshops, Thessaloniki, Greece, 2015.

[11] M. Santorum, A. Front, and D. Rieu, "ISEAsy: A Social Business Process Management Platform," in Business Process Management Workshops, N. Lohmann, M. Song, and P. Wohed, Eds., ed: Springer, 2013, pp. 125137.

[12] Y. Liu, Y. Tang, and J. Chen, "Interoperation based Business Process Management over Crossing Social Networks," International Journal of Grid and Distributed Computing, vol. 9, pp. 207-216, 2016.

[13] N. Alexopoulou, M. Nikolaidou, and C. Stary, "Blending BPMS with Social Software for KnowledgeIntense Work: Research Issues," in Enterprise, BusinessProcess and Information Systems Modeling, S. Nurcan, H. A. Proper, P. Soffer, J. Krogstie, R. Schmidt, T. Halpin, et al., Eds., ed: Springer, 2013, pp. 18-31.

[14] W. M. P. Van der Aalst, A. H. M. Ter Hofstede, and M. Weske, "Business Process Management: A Survey," in Business Process Management, A. H. M. ter Hofstede and M. Weske, Eds., ed Heidelberg: Springer, 2003, pp. 1-12.

[15] R. Liu, S. Agarwal, R. R. Sindhgatta, and J. Lee, "Accelerating Collaboration in Task Assignment Using a Socially Enhanced Resource Model," in Business Process Management, F. Daniel, J. Wang, and B. Weber, Eds., ed: Springer, 2013, pp. 251-258.

[16] D. Schall, B. Satzger, and H. Psaier, "Crowdsourcing tasks to social networks in BPEL4People," World Wide Web, vol. 17, pp. 1-32, 2014/01/01 2014.

[17] R. Karni and M. Levy, "Tagging Model for Enhancing Knowledge Transfer and Usage during Business Process Execution," in Business Process Management Workshops, ed: Springer, 2015, pp. 429-439.

[18] A. Al-Thuhli, M. Al-Badawi, Y. Baghdadi, and A. AlHamdani, "Migrating social business process to SOA," presented at the the 17th International Conference on Information Integration and Web-based Applications \& Services, Brussels, Belgium, 2015.

[19] P. Busch and P. Fettke, "Business Process Management under the Microscope: The Potential of Social Network Analysis," presented at the the 44th Hawaii International Conference on System Sciences, Hawaii, USA, 2011.

[20] F. Sánchez-Figueroa, J. C. Preciado, J. M. Conejero, and R. Rodríguez-Echeverría, "Designing Cooperative Social Applications in Healthcare by Means of SocialBPM," in Cooperative Design, Visualization, and Engineering, Y. Luo, Ed., ed: Springer, 2014, pp. 118-125. 
[21] O. Hatzi, D. Topali, M. Nikolaidou, and D. Anagnostopoulos, "Enabling Workflow Composition Within a Social Network Environment," in Business Process Management Workshops, N. Lohmann, M. Song, and P. Wohed, Eds., ed: Springer, 2014, pp. 91-103.

[22] M. J. Buco, H. Jamjoom, M. Podlaseck, and H. Qu, "Social Computing and Governance in an Enterprise Service for Managing Business Processes," presented at the 2009 World Conference on Services - II, Bangalore, India, 2009.

[23] O. Hatzi, G. Meletakis, P. Katsivelis, A. Kapouranis, M. Nikolaidou, and D. Anagnostopoulos, "Extending the Social Network Interaction Model to Facilitate Collaboration through Service Provision," in Enterprise, Business-Process and Information Systems Modeling, I. Bider, K. Gaaloul, J. Krogstie, S. Nurcan, H. A. Proper, R. Schmidt, et al., Eds., ed, 2014, pp. 94-108.

[24] R. Schmidt, "A Framework for the Support of Value Co-creation by Social Software," in Business Process Management Workshops, F. Daniel, K. Barkaoui, and S. Dustdar, Eds., ed: Springer, 2012, pp. 242-252.

[25] R. Schmidt and S. Nurcan, "BPM and Social Software," presented at the Business Process Management Workshops, Milano, Italy, 2008.

[26] S. Erol, M. Granitzer, S. Happ, S. Jantunen, B. Jennings, P. Johannesson, et al., "Combining BPM and social software: contradiction or chance?," Journal of Software Maintenance and Evolution: Research and Practice, vol. 22, pp. 449-476, 2010.

[27] L. Brehm and R. Schmidt, "Potential Benefits of Using Social Software in ERP-Based Business Process Management," in Multidimensional Views on Enterprise Information Systems, F. Piazolo and M. Felderer, Eds., ed: Springer, 2016, pp. 71-83.

[28] M. E. Rangiha and B. Karakostas, "Towards a MetaModel for Goal-Based Social BPM," in Business Process Management Workshops, N. Lohmann, M. Song, and P. Wohed, Eds., ed: Springer, 2014, pp. 104-112.

[29] P. Mathiesen, J. Watson, W. Bandara, and M. Rosemann, "Applying Social Technology to Business Process Lifecycle Management," presented at the BPM 2011 International Workshops, Clermont-Ferrand, France, 2011.

[30] M. Hauder, "Bridging the gap between social software and business process management: A research agenda," presented at the 7th International Conference on Research Challenges in Information Science, Paris, France, 2013.

[31] R. Cerenkovs and M. Kirikova, "Supporting Introduction of Social Interaction in Business Processes," in Perspectives in Business Informatics Research, B. Johansson, B. Andersson, and N. Holmberg, Eds., ed: Springer, 2014, pp. 187-201.

[32] N. Pereira, D. Vera, and H. G. Miller, "Business Process Management and the Social Web," IT Professional, vol. 13, pp. 58-59, 2011.

[33] B. S. Romeck, "Where the Buck Stops: Accountability in Reformed Public Organizations," in Transforming Government: Lessons from the Reinvention Laboratories, P. W. Ingraham, J. R. Thompson, and R. P. Sanders, Eds., ed San Fransisco: Jossey-Bass, 1997, pp. 192-219.

[34] M. Hill and P. Hupe, Implementing Public Policy: Governance in Theory and in Practice: SAGE Publications Ltd, 2002.

[35] M. Hill, The Public Policy Process, 6th ed. New York, USA: Routledge, 2013.
[36] E. Choudhury and S. Ahmed, "The shifting meaning of governance: Public accountability of third sector organizations in an emergent global regime," International Journal of Public Administration, vol. 25, pp. 561-588, 2002.

[37] J. Gortmaker, M. Janssen, and R. W. Wagenaar, "Accountability of Electronic Cross-Agency ServiceDelivery Processes," in Electronic Government: 4th International Conference, EGOV 2005, Copenhagen, Denmark, August 22-26, 2005. Proceedings, M. A. Wimmer, R. Traunmüller, A. Grönlund, and K. V. Andersen, Eds., ed Berlin Heidelberg: Springer, 2005, pp. 49-56.

[38] M. Janssen and M. A. Wimmer, "Introduction to Policy-Making in the Digital Age," in Policy Practice and Digital Science: Integrating Complex Systems, Social Simulation and Public Administration in Policy Research, M. Janssen, M. A. Wimmer, and A. Deljoo, Eds., ed: Springer, 2015, pp. 1-14. 